\title{
Laparoscopic observations of follicular rupture in the Japanese macaque (Macaca fuscata)
}

\author{
H. Nigi \\ Japan Monkey Centre, Kurisu 55, Inuyama, Aichi, 484 Japan
}

The development of laparoscopic techniques has facilitated serial observations of ovaries without damage to the animals. However, direct observations of the process of ovulation in primates are limited because of the difficulty of determining the exact moment of ovulation. Laparoscopic techniques have been applied to study of the Japanese macaque (Nigi, 1977) and the present paper describes the two types of ovulation which have been observed.

The moment of follicular rupture was observed during 6 cycles in 5 macaques (Macaca fuscata) which were over 6 years old and weighed $6 \cdot 8-11 \cdot 3 \mathrm{~kg}$. All details of the husbandry and laparoscopy procedures were as described by Nigi (1977). The first laparoscopy was carried out in the morning and the second 2-4 h later depending on the follicular appearance. Anaesthesia was induced and maintained by injections of ketamine hydrochloride, the longest period of anaesthesia being $5 \mathrm{~h}$. In all cases, the observations were conducted with as little manipulation of the ovary as possible to avoid the possibility of induced rupture of the follicle.

\section{Observations}

Ovulation occurred in the afternoon in all 6 cycles, and two types of rupture were distinguished.

Type 1 . This was observed in 3 cycles in 2 monkeys and was characterized by a rapid exudation of follicular fluid. In all instances, the translucent preovulatory follicle protruded from the ovarian surface through a discontinuity of the tunica albuginea (PI. 1, Figs 1 and 2). Full protrusion was achieved in only $10 \mathrm{sec}$ in one monkey, and in 3 and $110 \mathrm{~min}$ in the 2 cycles of the other. There was no increase in the size of the whole ovary; the part covered with the tunica appeared to be diminishing in size whilst the clear follicle was enlarging. The follicular surface was smooth and taut. In one follicle the follicular fluid abruptly became haemorrhagic just before the rupture, but in the other two there was no change. At rupture the follicular fiuid, mixed with blood, left the apex of the follicle so quickly (within 1-2 sec) that no cumulus mass was detected. The ruptured follicle and the ovary then collapsed (PI. 1, Fig. 3), but began to swell again $80 \mathrm{~min}$ after rupture in one case, and $120 \mathrm{~min}$ in the other two.

Type II. In the 3 examples of this type of rupture the follicular fluid was exuded gradually through one of the reddish diffuse areas which appeared on the surface of the preovulatory follicle (Pl. 1, Fig. 4). In one follicle, several reddish diffuse spots appeared on the surface of the translucent, protruding follicle $40 \mathrm{~min}$ after the start of protrusion, and each spot spread irregularly. After a further $10 \mathrm{~min}$, clear follicular fluid began to exude through one of the spots and continued to flow very slowly during the next $45 \mathrm{~min}$. The cumulus mass was not detected. In the other two instances, the preovulatory follicle was covered with the tunica albuginea until the follicular fluid began to flow, although the tunica appeared to have thinned considerably. The follicular surface was smooth and tense. Several diffuse spots appeared at the apex of one of these follicles (A) and 7 min later the spots amalgamated to form two large diffuse areas; the follicular fluid exuded slowly from one of these areas (Pl. 1, Figs 4, 5 and 6). In the other follicle (B) one irregular diffuse spot gradually spread and $52 \mathrm{~min}$ later the fluid began to run out from the central part. The outflow continued for $3 \mathrm{~min} 20 \mathrm{sec}$ from Follicle A and for $28 \mathrm{~min}$ from Follicle B. The fluid from both follicles was at first clear, but after $2 \mathrm{~min} 30 \mathrm{sec}$ (Follicle A) and $15 \mathrm{~min}$ (Follicle B) it became reddish. A mass assumed to be the cumulus mass left Follicles A and B at 3 min and 20 min respectively after the beginning of the fluid outflow. In all 3 examples of Type II rupture, the ovaries began to swell again 55-75 min after collapse. 
In the 6 ovaries in which follicular rupture was observed a clear and round ovulation point was distinguished on the surface of the follicle which became fully swollen again 18-24 h after rupture.

\section{Discussion}

No significant effect of laparoscopy and anaesthesia on ovulation has been reported in previous laparoscopic studies of primates (Jewett \& Dukelow, 1973; Rawson \& Dukelow, 1973a; Dukelow, 1975; Nigi, 1977). Because manipulation to the ovary was avoided as much as possible in the present study, I believe that the follicular ruptures observed were not surgically induced but occurred spontaneously. Follicular rupture and release of the ovum have been reported to take approximately $30 \mathrm{sec}$ in Macaca fascicularis (Rawson \& Dukelow, 1973b; Dukelow, 1975). Similarly rapid ovulation was observed in this study, but a slower process was also seen. Such differences may be correlated with morphological variations in the preovulatory follicles (Nigi, 1977). The smooth and tense surface of the preovulatory follicle in Macaca fuscata suggests that the intrafollicular fluid may exert pressure on the follicular membrane. However, the round ovulation point does not suggest an abrupt rupture due to internal pressure, as has been stated by Asdell (1962). Moreover, in other species there is no significant increase in the intrafollicular pressure at ovulation (Blandau \& Rumery, 1963; Espey \& Lipner, 1963; Blandau, 1966; Stähler, Spätling, Bethge, Daume \& Buchholz, 1974). The reddish diffuse area typical of the Type II ruptures apparently differs from the 'stigma' (a circumscribed area edged by a definite ring of vessels) observed in the rat (Blandau, 1955, 1966), and has never been reported for other primate species. The diffuse area is presumably closely related to ovulation and may be a weakened section of the follicular wall, although the cause of its appearance cannot yet be explained.

This study was supported by a grant-in-aid for the Special Project Research (Experimental Animals: No. 012205) from the Ministry of Education, Science and Culture of Japan.

\section{References}

Aspell, S.A. (1962) The mechanism of ovulation. In The Ovary, vol. I, pp. 435-449. Ed. S. Zuckerman. Academic Press, New York.

BlandaU, R.J. (1955) Ovulation in the living albino rat. Fert. Steril. 6, 391-400.

BLANDAU, R.J. (1966) The mechanism of ovulation. In Ovulation, pp. 3-15. Ed. R. B. Greenblatt. J. B. Lippincott Co., Philadelphia.

Blandau, R.J. \& RUmery, R.E. (1963) Measurements of intra-follicular pressure in ovulatory and preovulatory follicles of the rat. Fert. Steril. 14, 330-341.

DUkelOW, W.R. (1975) The morphology of follicular development and ovulation in non-human primates. J. Reprod. Fert., Suppl. 22, 23-51.

ESPEY, L.L. \& LIPNER, H. (1963) Measurements of intrafollicular pressures in the rabbit ovary. $\mathrm{Am} . J$. Physiol. 205, 1067-1072.
Jewett, D.A. \& Dukelow, W.R. (1973) Follicular observation and laparoscopic aspiration techniques in Macaca fascicularis. J. med. Primat. 2, 108-113.

Nigi, H. (1977) Laparoscopic observations of ovaries before and after ovulation in the Japanese monkey (Macaca fuscata). Primates 18, (in press).

Rawson, J.M.R. \& Dukelow, W.R. (1973a) Effect of laparoscopy and anesthesia on ovulation, conception, gestation and lactation in a Macaca fascicularis. Lab. Primat. Newsletter 12, 4-5.

Rawson, J.M.R. \& Dukelow, W.R. (1973b) Observation of ovulation in Macaca fascicularis. $J$. Reprod. Fert. 34, 187-190.

Stähler, E., Spätling, L., Bethge, H.D., Daume, E. \& BuchHolz, R. (1974) Induction of ovulation in human ovaries perfused in vitro. Arch. Gynak. 217, $1-15$. 
PI. I1.
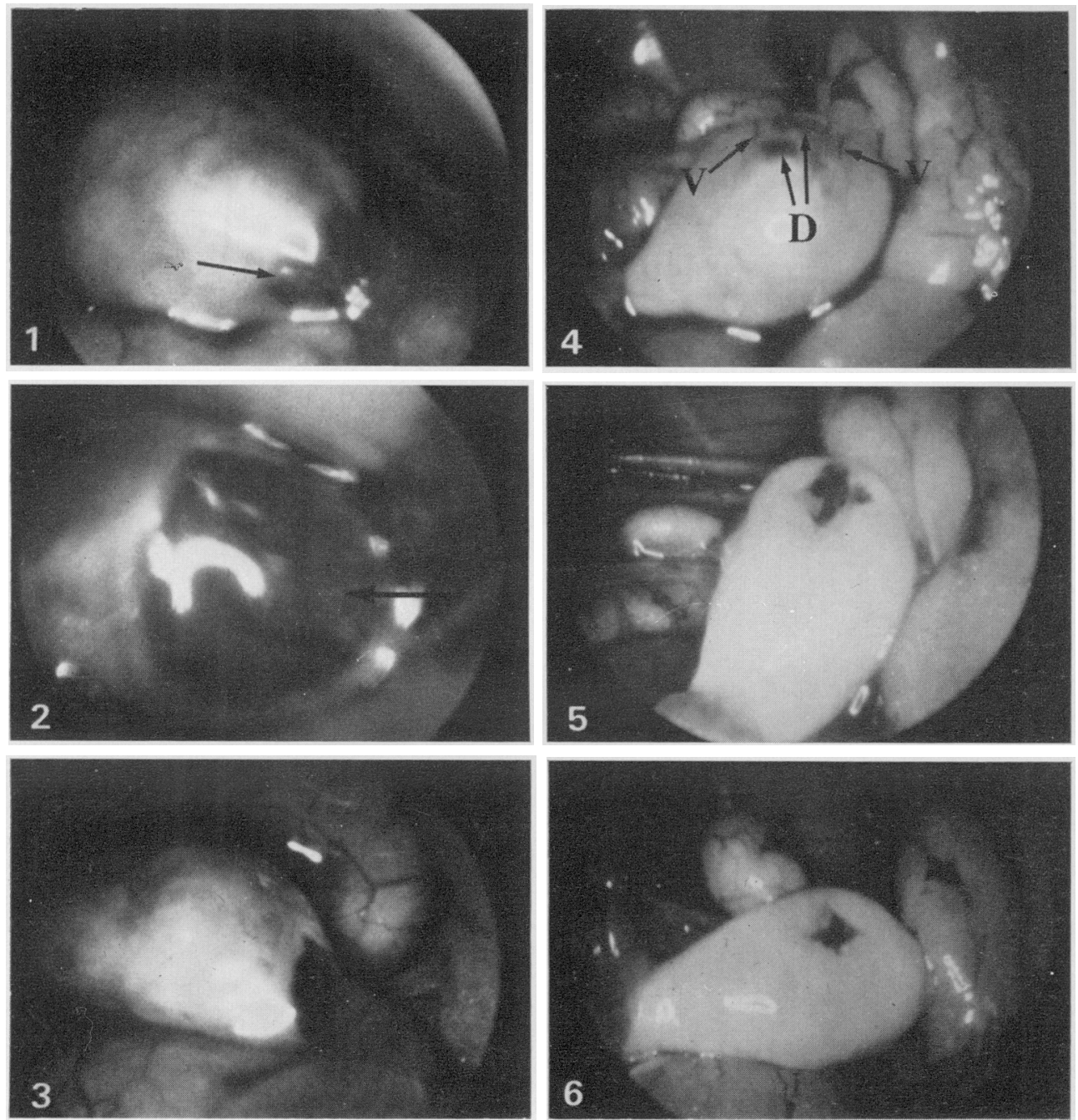

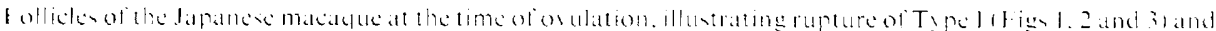

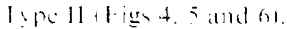

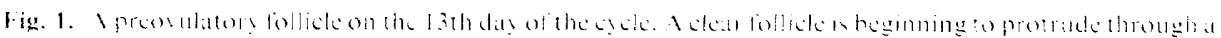

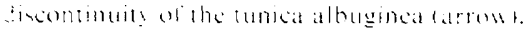

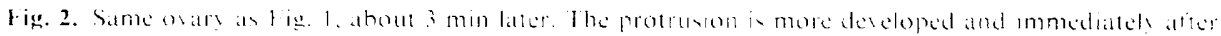

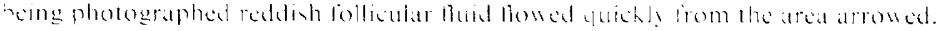

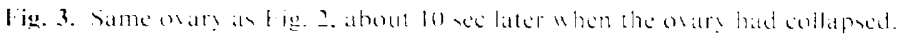

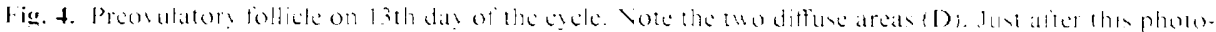

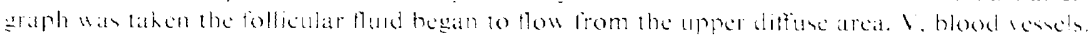

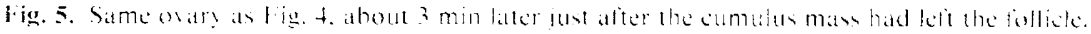

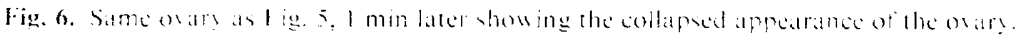

